\title{
n-3 PUFA in CVD: influence of cytokine polymorphism
}

\author{
C. von Schacky \\ Preventive Cardiology, Medizinische Klinik und Poliklinik Innenstadt, University of Munich, Ziemssenstraße 1, \\ D-80336 München, Germany
}

\begin{abstract}
In their current guidelines cardiac societies recommend the consumption of the two $n-3$ fatty acids EPA and DHA to prevent cardiovascular complications. Cardiovascular events are reduced by EPA and DHA, because they are antiarrhythmic, mitigate the course of atherosclerosis and stabilise plaque. As atherosclerosis is considered an inflammatory disorder a number of studies have investigated the anti-inflammatory mechanisms of EPA and DHA in a cardiovascular context in human dietary intervention studies. Pro-inflammatory cytokines, or cytokines reflecting inflammatory processes, e.g. IL-1 $\beta$, IL-2, IL-6, TNF $\alpha$, platelet-derived growth factor (PDGF)-A and -B and monocyte chemoattractant protein-1 (MCP-1), are reduced by ingestion of EPA and DHA by human subjects. Interestingly, C-reactive protein remains largely unaltered. However, in in vitro and animal models, but less so in human subjects, soluble cytokines reflecting interactions between blood cells and the vessel wall, such as intercellular adhesion molecule-1 and vascular cell adhesion molecule-1, are reduced. Moreover, in contrast to common expectations, oxidative stress seems to be reduced after ingestion of EPA and DHA, at least as indicated by measurement of urinary $F_{2}$ isoprostane excretion. Notably, for PDGF-A and -B and for MCP-1 the reduction has been demonstrated to occur at the gene expression level, which indicates that a deliberate change in diet can alter gene expression quantitatively. The precise underlying mechanism, however, remains to be clarified, but might involve PPAR, NF- $\mathrm{KB}$ and/or the eicosanoid system. The same holds true for the mechanisms by which levels of other cytokines are altered by EPA and DHA.
\end{abstract}

\section{Cytokines: Growth factors: Coronary artery disease}

The World's most important cardiac societies have issued guidelines that recommend the intake of the two marine $n$-3 fatty acids EPA and DHA at $1 \mathrm{~g} / \mathrm{d}$ for CVD prevention, treatment after a myocardial infarction and prevention of sudden death and secondary disease (De Backer et al. 2003; Priori et al. 2003; Van der Werf et al. 2003; Smith et al. 2006). National cardiac societies have followed suit (Wirth \& Gohlke, 2005). These recommendations are based not only on intervention trials with these $n-3$ fatty acids (Burr et al. 1989, 2003; The GISSI Prevenzione Group, 1999; Marchioli et al. 2002; Yokoyama et al. 2003), but also on a wealth of literature describing mechanisms of actions, animal models, studies with surrogate and intermediate factors and other aspects (von Schacky, 1987, 2003). Taken together, the scientific basis of the current guidelines is so strong that they have been established despite a null result in a recent Cochrane analysis (Hooper et al. 2006).
EPA and DHA have been demonstrated not only to have an antiarrhythmic effect (Leaf et al. 2005; Raitt et al. 2005), but also to mitigate the course of coronary atherosclerosis (von Schacky et al. 1999) and to stabilize unstable plaque, e.g. in carotid arteries (Thies et al. 2003). These two findings are manifestations of an anti-inflammatory effect of EPA and DHA, currently used in the treatment of inflammatory disorders such as rheumatoid arthritis (Kremer, 2000). For some time atherosclerosis has been considered to be a disease with an inflammatory component (for example, see Ross, 1999). The present review considers investigations aimed at unravelling the mechanisms by which EPA and DHA exert their antiinflammatory effects through alterations of cytokine metabolism. Since differences exist in cytokine metabolism in vitro $v$. in vivo and in experimental animals $v$. in human subjects the present review will largely focus on work done in human subjects. 
Cytokines related to inflammation and atherosclerosis

$$
I L-1 \beta
$$

IL-1 $\beta$ is an important cytokine that has a plethora of actions, including a pronounced pro-inflammatory effect and increasing the expression of adhesion molecules (Dinarello, 2006). Levels of IL-1 $\beta$ decrease by $61-90 \%$ when healthy volunteers and patients with rheumatoid arthritis ingest doses of between 2.7 and $5.8 \mathrm{~g}$ EPA and DHA/d (for review, see James et al. 2000). Furthermore, IL-1 $\beta$ levels associated with stimulation by strenuous exercise (a marathon run) are not influenced by previous ingestion of $3.6 \mathrm{~g}$ EPA and DHA/d (Toft et al. 2000), which suggests that IL-1 $\beta$ levels clearly respond to a strong stimulus. These findings might partially explain why infectious complications are not seen more frequently in large-scale intervention trials using EPA and DHA (von Schacky \& Harris, 2006).

\section{IL-6}

IL-6 is a cytokine that together with a soluble IL-6 receptor plays an important role in perpetuating an inflammatory state (Scheller et al. 2006). IL-6 is generally reduced, as assessed ex vivo, after supplementation of the human diet with $n$-3 fatty acids (for review, see Calder, 2005). In the supernatant fraction of unstimulated mononuclear cells the reduction is more pronounced after $0.3 \mathrm{~g}$ EPA and DHA/d than after 1.0 or $2.0 \mathrm{~g}$ EPA and DHA/d (Trebble et al. 2003). However, in the supernatant fraction of stimulated mononuclear cells the reduction is clearly dose-related (Trebble et al. 2003).

\section{IL-10}

An epidemiological study (Ferrucci et al. 2006) has shown that low levels of this anti-inflammatory compound are associated with low levels of DHA. After treatment for 1 year with $3.4 \mathrm{~g}$ EPA and DHA/d, the IL-10 levels of forty-five recipients of heart transplants were found to be decreased (Holm et al. 2001). In healthy volunteers after supplementation with $7 \mathrm{~g}$ EPA and DHA/d for 4 weeks IL10 mRNA steady-state levels were found to be unaltered in either unstimulated mononuclear cells or monocytes that had been adherence-activated ex vivo (Baumann et al. 1999). There have been no other reports of studies in human subjects. Thus, there is at present no clear picture of the effects of EPA and DHA on levels of IL- 10 .

\section{$T N F \alpha$}

TNF $\alpha$ is a pro-inflammatory cytokine that has a large number of effects, among them increased body temperature, reduced appetite and stimulation of other immunmodulatory cytokines (Grimble, 1996). TNF is thought to be a propagator of atherosclerosis (Ross, 1999). The effects of fish oil on TNF $\alpha$ production by peripheral blood mononuclear cells have been investigated in eleven studies of healthy volunteers, of which six studies have demonstrated a suppressive effect (for review, see Grimble et al. 2002). These apparently discrepant findings can be explained by the effects of inherent $\mathrm{TNF} \alpha$ production and by polymorphisms in the TNF $\alpha$ and lymphotoxin $\alpha$ genes (Grimble et al. 2002). These polymorphisms might also explain an unexpected increase in TNF in recipients of heart transplants after supplementation with $3.4 \mathrm{~g}$ EPA and DHA/d for 1 year (Holm et al. 2001). In a dose-response study of healthy volunteers levels of TNF $\alpha$ in the supernatant fraction of unstimulated and stimulated mononuclear cells was shown to decrease (Trebble et al. 2003). Interestingly, the decrease was found to be less pronounced after consuming $2 \cdot 0 \mathrm{~g}$ EPA and DHA/d than after consuming $1.0 \mathrm{~g}$ EPA and DHA/d.

DHA, but not EPA, reduces the expression of proinflammatory IL-1, IL-6 and TNFo in vitro (De Caterina et al. 2006).

\section{Platelet-derived growth factor}

Platelet-derived growth factor (PDGF) stimulates smooth muscle cell proliferation and plays a role in the migration of these cells into neointima following injury and in atherosclerosis (Raines, 2004). PDGF is thought to play a major role in the proliferation of atherosclerotic lesions (Ross, 1999). In volunteers ingesting $7 \mathrm{~g}$ EPA and DHA/d levels of mRNA coding for PDGF-A and -B were found to be reduced by $58 \%$ after 1 week and by $70 \%$ after 6 weeks, with these levels remaining constant in controls on an unaltered Western diet (Kaminski et al. 1993). This finding was the first demonstration that a deliberate change in diet can alter gene expression quantitatively. In a subsequent study, with the same dose of EPA and DHA but comparing it with $7 \mathrm{~g} n-6$ fatty acids/d and $7 \mathrm{~g} n-9$ fatty acids/d (Baumann et al. 1999), the reduction in the levels of PDGF-A and -B mRNA was found to be quantitatively less pronounced (for PDGF-A -25 (SD 10) \%, for PDGF-B -31 (SD 13) \%) in non-stimulated mononuclear cells. However, after cell adherence for $4 \mathrm{~h}$ or $20 \mathrm{~h}$ the reduction was found to persist to a quantitatively similar extent (Baumann et al. 1999). Lower doses of EPA and DHA $(0 \cdot 3,0.6$ or $0.9 \mathrm{~g} n-3$ fatty acids/d) have no effect on serum mitogenic activity or serum PDGF levels (Wallace et al. 2000).

\section{Monocyte chemoattractant protein-1}

Monocyte chemoattractant protein-1 (MCP-1), acting through its receptor chemokine $(\mathrm{C}-\mathrm{C}$ motif) receptor 2 , appears to play an early and important role in the recruitment of monocytes to atherosclerotic lesions and in the formation of intimal hyperplasia after intimal injury (Charo $\&$ Taubman, 2004). Supplementation with dietary $n-3$ fatty acids (EPA and DHA), but not $n-6$ or $n-9$ fatty acids, at $7 \mathrm{~g}$ /d for 4 weeks reduces MCP-1 mRNA levels in unstimulated mononuclear cells ex vivo by $40 \%$ (Baumann et al. 1999). After stimulation of the cells by adherence for $4 \mathrm{~h}$ and $20 \mathrm{~h}$ MCP- 1 mRNA levels are reduced by 35 (SD 20) $\%$ and 30 (SD 8) \% respectively (Baumann et al. 1999). It is quite likely that the reductions in gene expression translate into reduced levels of MCP-1 before and after stimulation in vivo, although the direct proof will be quite difficult to obtain. Evidence from in vitro studies 
(De Caterina \& Massaro, 2005) indicates that both EPA and DHA decrease agonist-induced activation of NF- $\mathrm{KB}$ and increase PPAR. This effect might very well play a role in the reduced gene expression for PDGF-A and -B and for MCP-1 in vivo after EPA and DHA.

\section{C-reactive protein}

C-reactive protein is a marker of systemic inflammation that is currently considered to be a risk factor for CVD (Tsimikas et al. 2006). Given the anti-inflammatory and anti-atherosclerotic effects of EPA and DHA, reduced levels of C-reactive protein would be expected to occur after supplementation. While an epidemiological study (Pischon et al. 2003) has shown an inverse relationship between the intake of EPA and DHA and levels of C-reactive protein, human intervention studies (for review, see Mori \& Beilin, 2004) have not found a reduction in C-reactive protein levels after ingestion of EPA and DHA. Thus at present no clear picture of the relationship between EPA and DHA and C-reactive protein has emerged.

\section{Cytokines related to endothelial activation}

Vascular cell adhesion molecule (VCAM)-1, intercellular adhesion molecule-1 (ICAM-1) and E-selectin have a role in the pathogenesis of atherosclerosis (Hope \& Meredith, 2003). Plasma levels can be measured because soluble (s) VCAM and sICAM are shed from the cell surface. Plasma levels of sE-selectin can also be measured (Roldan et al. 2003). Levels of VCAM and ICAM correlate to some extent with the presence of clinical atherosclerosis (Hope $\&$ Meredith, 2003). However, VCAM-1 and ICAM-1 have a role in the early phase of the development of the atherosclerotic lesion, i.e. in monocyte recruitment by endothelial cells, before the appearance of macrophages (foam cells) in the intima (De Caterina \& Massaro, 2005). E-selectin is expressed on the endothelial surface slightly earlier in the sequence of events (Roldan et al. 2003). sVCAM-1, sICAM-1 and sE-selectin are considered to be markers of endothelial activation (Hope \& Meredith, 2003; Roldan et al. 2003). Whether they are risk factors for atherosclerosis or its clinical events is a matter of debate.

Stimulated endothelial cells express less sVCAM, sICAM or sE-selectin in the presence of $n-3$ fatty acids, with DHA being more potent than EPA (De Caterina et al. 2004). DHA reduces mRNA levels by inhibition of the activation of the NF- $\kappa \mathrm{B}$ system of transcription factors (De Caterina et al. 2004). Corresponding findings from studies in experimental animals have been published (for review, see Calder, 2004).

Studies in human subjects have yielded less clear results. In a randomized study of forty-one male smokers with hyperlipidaemia (Seljeflot et al. 1998) $4.8 \mathrm{~g}$ EPA and DHA/d was shown to increase levels of sVCAM-1 and sEselectin. In middle-aged healthy volunteers (Thies et al. 2001) supplementation with $1 \mathrm{~g}$ EPA and DHA/d for 12 weeks was found to reduce levels of sVCAM-1 $(-28 \%)$ and sE-selectin $(-17 \%)$, while levels of sICAM-1 were unaltered. In another 12-week randomized double-blind study of healthy subjects by the same group (Miles et al. 2001) levels of all three compounds were found to be unaltered after fish oil supplementation. In a 1-year doubleblind study of 300 patients after a myocardial infarction (Grundt et al. 2003) treatment with EPA and DHA was not found to reduce levels of SICAM or sE-selectin. In individuals with type 2 diabetes, however, levels of sE-selectin are reduced after treatment with EPA or DHA (Nomura et al. 2003; Woodman et al. 2003). Administration of $2 \cdot 4 \mathrm{~g}$ EPA and DHA/d to 171 elderly men at risk for coronary artery disease has been shown to increase sVCAM (Berstad et al. 2003). A randomized study (Eschen et al. 2004) comparing EPA and DHA at doses of $2.0 \mathrm{~g} / \mathrm{d}$ and $6.6 \mathrm{~g} / \mathrm{d}$ in healthy subjects has shown a decrease in sE-selectin only when fed at a dose of $6.6 \mathrm{~g} / \mathrm{d}$. In a large (563 elderly subjects) 3-year randomized study that compared (using a factorial design) dietary advice, $2 \cdot 4 \mathrm{~g}$ EPA and DHA/d and no treatment (Hjerkinn et al. 2005) EPA and DHA was found to reduce levels of sICAM.

Thus, while a clear picture has emerged in vitro and in animal studies, demonstrating reductions in plasma levels of sVCAM, sICAM and sE-selectin, investigations in human subjects have yielded mixed results. This disparity may be related to differences in populations studied and doses used.

\section{Oxidative stress}

The measurement of urinary $F_{2}$ isoprostane excretion by GC-MS is currently thought to best reflect oxidative stress in vivo (Mori \& Beilin, 2004). In contrast to theoretical concerns and earlier observations with less-refined methodology, oxidative stress has been consistently shown to be reduced after ingestion of EPA and DHA both in combination and individually (Mori \& Beilin, 2004). Reduced oxidative stress is thought to contribute to the anti-atherosclerotic actions of $n-3$ fatty acids, possibly through immunomodulation and decreased leucocyte activation (Mori \& Beilin, 2004).

\section{Conclusion}

Taken together EPA and DHA reduce levels of the proinflammatory cytokines IL-1 $\beta$, IL- 6 and TNFo in human subjects. Moreover, mRNA levels of pro-atherosclerotic growth factors, such as PDGF-A and -B, and MCP-1 are reduced in mononuclear cells after supplementing the human diet with EPA and DHA. The cytokines and growth factors mentioned play a role in the propagation of the atherosclerotic lesion. In vitro the levels of SICAM, SVCAM and sE-selectin are reduced by the presence of EPA or DHA. These cytokines reflect endothelial activation. Data from human studies are less clear cut, probably because endothelial activation is transient. It is currently thought that the effects of EPA and DHA on cytokines and growth factors are the mechanisms responsible for the anti-atherosclerotic action of these $n-3$ fatty acids. 


\section{References}

Baumann KH, Hessel F, Larass I, Müller T, Angerer P, Kiefl R \& von Schacky C (1999) Dietary omega-3, omega-6, and omega9 unsaturated fatty acids and growth factor and cytokine gene expression in unstimulated and stimulated monocytes. A randomized volunteer study. Arteriosclerosis, Thrombosis, and Vascular Biology 19, 59-66.

Berstad P, Seljeflot I, Veierod MB, Hjerkinn EM, Arnesen H \& Pedersen JH (2003) Supplementation with fish oil affects the association between very long-chain polyunsaturated fatty acids in serum non-esterified fatty acids and soluble vascular cell adhesion molecule-1. Clinical Science 105, 13-20.

Burr ML, Ashfield-Watt PAL, Dunstan FDJ, Fehily AM, Breay P, Ashton T, Zotos PC, Haboubi NAA \& Elwood PC (2003) Lack of benefit of dietary advice to men with angina, results of a controlled trial. European Journal of Clinical Nutrition 57, 193-200.

Burr ML, Fehily AM, Gilbert JF, Rogers S, Holliday RM, Sweetnam PM, Elwood PC \& Deadman NM (1989) Effects of changes in fat, fish, and fibre intakes on death and myocardial infarction: diet and reinfarction trial (DART). Lancet ii, 757-761.

Calder PC (2004) n-3 fatty acids and cardiovascular disease: evidence explained and mechanisms explored. Clinical Science 107, 1-11.

Calder PC (2005) Polyunsaturated fatty acids and inflammation. Biochemical Society Transactions 33, 423-427.

Charo IF \& Taubman MB (2004) Chemokines in the pathogenesis of vascular disease. Circulation Research 95, 858-866.

De Backer G, Ambrosioni E, Borch-Johnsen K, Brotons C, Cifkova R, Dallongeville J et al. (2003) European guidelines on cardiovascular disease prevention in clinical practice. Third Joint Task Force of European and Other Societies on Cardiovascular Disease Prevention in Clinical Practice. European Heart Journal 24, 1601-1610.

De Caterina R, Madonna R \& Massaro M (2004) Effects of omega-3 fatty acids on cytokines and adhesion molecules. Current Atherosclerosis Reports 6, 485-491.

De Caterina R \& Massaro M (2005) Omega-3 fatty acids and the regulation of expression of endothelial pro-atherogenic and pro-inflammatory genes. Journal of Membrane Biology 206, 103-116.

De Caterina R, Zampolli A, Del Turco S, Madonna R \& Massaro M (2006) Nutritional mechanisms that influence cardiovascular disease. American Journal of Clinical Nutrition 83, Suppl., 421S-426S

Dinarello CA (2006) Interleukin 1 and interleukin 18 as mediators of inflammation and the aging process. American Journal of Clinical Nutrition 83, Suppl., 447S-455S.

Eschen O, Christensen JH, De Caterina R \& Schmidt EB (2004) Soluble adhesion molecules in healthy subjects: a dose response study using n-3 fatty acids. Nutrition and Metabolism in Cardiovascular Disease 14, 180-185.

Ferrucci L, Cherubini A, Bandinelli S, Bartali B, Corsi A, Lauretani F, Ma A, Andres-Lacueva C, Senin U \& Gualnik JM (2006) Relationship of plasma polyunsaturated fatty acids to circulating inflammatory markers. Journal of Clinical Endocrinology and Metabolism 91, 398-400.

Grimble RF (1996) Interaction between nutrients, proinflammatory cytokines and inflammation. Clinical Science $\mathbf{9 1}$, 121-130.

Grimble RF, Howell WM, O’Reilly G, Turner SJ, Markovic O, Hirrell S, East JM \& Calder PC (2002) The ability of fish oil to suppress tumor necrosis factor $\alpha$ production by peripheral blood mononuclear cells in healthy men is associated with polymorphisms in genes that influence tumor necrosis factor $\alpha$ production. American Journal of Clinical Nutrition 76, 454-459.

Grundt H, Nilsen DW, Mansoor MA, Hetland O \& Nordoy A (2003) Reduction in homocysteine by $n-3$ polyunsaturated fatty acids after 1 year in a randomised double-blind study following an acute myocardial infarction: no effect on endothelial adhesion properties. Pathophysiology in Haemostasis and Thrombosis 33, 88-95.

Hjerkinn EM, Seljeflot I, Ellingsen I, Berstad I, Berstad P, Hjermann I, Sandvik L \& Arnesen H (2005) Influence of long-term intervention with dietary counseling, long-chain n-3 fatty acid supplements, or both on circulating markers of endothelial activation in men with long-standing hyperlipidemia. American Journal of Clinical Nutrition 81, 583-589.

Holm T, Berge RK, Anderassen AK, Ueland T, Kjekshus J, Simonsen S, Froland S, Gullestad L \& Aukrust P (2001) Omega-3 fatty acids enhance tumor necrosis factor-alpha levels in heart transplant recipients. Transplantation 72, 706-711.

Hooper L, Thompson RL, Harrison RA, Summerbell CD, Ness AR, Moore HJ et al. (2006) Risks and benefits of omega 3 fats for mortality, cardiovascular disease, and cancer: systematic review. British Medical Journal 332, 752-760.

Hope SA \& Meredith IT (2003) Cellular adhesion molecules and cardiovascular disease. Part II. Their association with conventional and emerging risk factors, acute coronary events and cardiovascular risk prediction. Internal Medical Journal 33, 450-462.

James MJ, Gibson RA \& Cleland LG (2000) Dietary polyunsaturated fatty acids and inflammatory mediator production. American Journal of Clinical Nutrition 71, Suppl., 343S-348S.

Kaminski WE, Jendraschak E, Kiefl R \& von Schacky C (1993) Dietary $\omega$-3 fatty acids lower levels of PDGF mRNA in human mononuclear cells. Blood 81, 1871-1879.

Kremer JM (2000) n-3 fatty acid supplements in rheumatoid arthritis. American Journal of Clinical Nutrition 71, Suppl., 349S-351S.

Leaf A, Albert CM, Josephson M, Steinhaus D, Kluger J, Kang JX, Cox B, Zhang H \& Schoenfeld D for the Fatty Acid Antiarrhythmia Trial Investigators (2005) Prevention of fatal arrhythmias in high-risk subjects by fish oil n-3 fatty acid intake. Circulation 112, 2762-2768.

Marchioli R, Barzi F, Bomba E, Chieffo C, Di Gregorio D, Di Mascio $\mathrm{R}$ et al. (2002) Early protection against sudden death by $n-3$ polyunsaturated fatty acids after myocardial infarction. Time-course analysis of the results of the Gruppo Italiano per lo Studio della Sopravvivenza nell'Infarcto Miocardio (GISSI) Prevenzione. Circulation 105, 1897-1903.

Miles EA, Thies F, Wallace FA, Powell JR, Hurst TL, Newsholme EA \& Calder PC (2001) Influence of age and dietary fish oil on plasma soluble adhesion molecule concentrations. Clinical Science 100, 91-100.

Mori TA \& Beilin LJ (2004) Omega-3 fatty acids and inflammation. Current Atherosclerosis Reports 6, 461-467.

Mori TA, Woodman RJ, Burke V, Puddey IB, Croft KD \& Beilin LJ (2003) Effect of eicosapentaenoic acid and docosahexaenoic acid in oxidative stress and inflammatory markers in treated type 2 diabetic subjects. Free Radical Biology and Medicine 7, $772-781$.

Nomura S, Kanazawa S \& Fukuhara S (2003) Effects of eicosapentaenoic acid on platelet activation markers and cell adhesion molecules in hyperlipidemic patients with type 2 diabetes. Journal of Diabetes and its Complications 17, 153-159.

Pischon T, Hankinson SE, Hotamisligil GS, Rifai N, Willett WC \& Rimm EB (2003) Habitual dietary intake of n-3 and n-3 fatty acids in relation to inflammatory markers among US men and women. Circulation 108, 155-160. 
Priori SG, Aliot E, Blomstrom-Lundqvist C, Bossaert L, Breithardt G, Brugada P et al. (2003) European Society of Cardiology update of the guidelines on sudden cardiac death of the European Society of Cardiology. European Heart Journal 24, 13-15.

Raines EW (2004) PDGF and cardiovascular disease. Cytokine and Growth Factor Reviews 15, 237-254.

Raitt MJ, Connor WE, Morris C, Kron J, Halperin B, Chugh SS et al. (2005) Fish oil supplementation and risk of ventricular tachycardia and ventricular fibrillation in patients with implantable defibrillators. Journal of the American Medical Association 293, 2884-2891.

Roldan V, Marin F, Lip GY \& Blann AD (2003) Soluble E-selectin in cardiovascular disease and its risk factors. A review of the literature. Thrombosis and Haemostasis 90, 1007-1020.

Ross R (1999) Atherosclerosis - an inflammatory disease. New England Journal of Medicine 340, 115-126.

Scheller J, Ohnesorge N \& Rose-John S (2006) Interleukin-6 trans-signaling in chronic inflammation and cancer. Scandinavian Journal of Immunology 63, 321-329.

Seljeflot I, Arnesen H, Brude IR, Nenseter MS, Drevon CA \& Hjermann I (1998) Effects of omega-3 fatty acids and/or antioxidants on endothelial cell markers. European Journal of Clinical Investigation 28, 629-635.

Smith SC, Allen J, Blair SN, Bonow RO, Brass LM, Fonarow GC et al. (2006) AHA/ACC Guidelines for secondary prevention for patients with coronary and other atherosclerotic vascular disease: 2006 update. Circulation 113, 2363-2372.

The GISSI Prevenzione Group (1999) Dietary supplementation with $n-3$ polyunsaturated fatty acids and vitamin $\mathrm{E}$ after myocardial infarction: results of the GISSI-Prevenzione trial. Gruppo Italiano per lo Studio della Sopravvivenza nell'Infarto miocardico. Lancet 354, 447-455.

Thies F, Garry JM, Yaqoob P, Rerkasem K, Williams J, Shearman CP, Gallagher PJ, Calder PC \& Grimble RF (2003) Association of n-3 polyunsaturated fatty acids with stability of atherosclerotic plaques: a randomised controlled trial. Lancet 361, 477-485.

Thies F, Miles EA, Nebe-von-Caron G, Powell JR, Hurst TL, Newsholme EA \& Calder PC (2001) Influence of dietary supplementation with long-chain n-3 or n-6 polyunsaturated fatty acids on blood inflammatory cell populations and functions and on plasma soluble adhesion molecules in healthy adults. Lipids 36, 1183-1193.

Toft AD, Thorn M, Ostrowski K, Asp S, Moller K, Iversen S, Hermann C, Sondergaard SR \& Pedersen BK (2000) N-3 polyunsaturated fatty acids do not affect cytokine response to strenuous exercise. Journal of Applied Physiology 89, 2401-2406.
Trebble T, Arden NK, Stroud MA, Wootton SA, Burdge GC, Miles EA, Ballinger AB, Thompson RL \& Calder PC (2003) Inhibition of tumour necrosis factor- $\alpha$ and interleukin 6 production by mononuclear cells following dietary fishoil supplementation in healthy men and response to antioxidant co-supplementation. British Journal of Nutrition 90, 405-412.

Tsimikas S, Willerson JT \& Ridker PM (2006) C-reactive protein and other emerging blood markers to optimize risk stratification of vulnerable patients. Journal of the American College of Cardiology 47, Suppl., C19-C31.

Van der Werf F, Ardissino D, Betriu A, Cokkinos DV, Falk E, Fox KA et al. (2003) Management of acute myocardial infarction in patients presenting with ST-segment elevation. The Task Force on the Management of Acute Myocardial Infarction of the European Society of Cardiology. European Heart Journal 24, 28-66.

von Schacky C (1987) Prophylaxis of atherosclerosis with marine omega-3 fatty acids - a comprehensive strategy. Annals of Internal Medicine 107, 890-899.

von Schacky C (2003) The role of omega-3 fatty acids in cardiovascular disease. Current Atherosclerosis Reports 5 , 139-145.

von Schacky C, Angerer P, Kothny W, Theisen K \& Mudra H (1999) The effect of dietary omega-3 fatty acids on coronary atherosclerosis. A randomized, double-blind, placebocontrolled trial. Annals of Internal Medicine 130, 554-562.

von Schacky C \& Harris WS (2007) Beneficial cardiovascular effects of omega-3 fatty acids. Cardiovascular Research $\mathbf{7 2}$, 310-315.

Wallace JM, McCabe AJ, Roche HM, Higgins S, Robson PJ, Gilmore WS, McGlynn H \& Strain JJ (2000) The effect of low-dose fish oil supplementation on serum growth factors in healthy humans. European Journal of Clinical Nutrition 54, 690-694.

Wirth A \& Gohlke H (2005) Rolle des Korpergewichts fur die Pravention der koronaren Herzkrankheit (Role of body weight for the prevention of coronary heart disease). Zeitschrift für Kardiologie 94, Suppl. 3, III/22-III/29.

Woodman RJ, Mori TA, Burke V, Puddey IB, Barden A, Watts GF \& Beilin LJ (2003) Effects of purified eicosapentaenoic acid and docosahexaenoic acid on platelet, fibrinolytic and vascular function in hypertensive type 2 diabetic patients. Atherosclerosis 166, 85-93.

Yokoyama M \& Origasea H for the JELIS Investigators (2003) Effects of eicosapentaenoic acid on cardiovascular events in Japanese patients with hypercholesterolemia: Rationale, design, and baseline characteristics of the Japan EPA Lipid Intervention Study (JELIS). American Heart Journal 146, 613-620. 